\title{
ACTION OF LEPTIN ON BONE AND ITS RELATIONSHIP TO MENOPAUSE
}

\author{
Martin Petzel
}

Department of gynaecology and obstetrics, University hospital Ostrava, 17. listopadu 1790, Ostrava-Poruba, 70852, Czech Republic, m.petzel@seznam.cz

Received: October 5, 2007; Accepted: November 2, 2007

Key words: Leptin/Bone/Osteoporosis/Menopause/Hormone replacement therapy

Backround: Leptin a cytokine protein secreted by adipose tissue raises considerable interest as a potential mediator of the protective effects of fat mass on bone tissue. After menopause heavier women conserve bone mass better than those with lower body weight. The protective effect of obesity on bone mass has been ascribed to a high body fat content. As Leptin levels reflect the body fat content it has emerged as a possible mediator of these protective effects.

Methods: A search of the available literature focused on the role of leptin on bone tissue.

Results: Both peripheral and central action of leptin on bone metabolism have been proposed. In vitro and in vivo evidence supports the hypothesis that leptin can act directly or indirectly on bone remodelling by modulating both osteoblast and osteoclast activities. However, studies in humans have not yet been able to confirm these actions possibly because of the shifting balance between stimulatory direct action and suppressive indirect action of leptin on bones via the hypothalamus. The effects of oestrogen decline and deficiency during natural or artificially induced menopause and administration of hormone replacement therapy has on leptin production remains controversial. Various studies have shown differences in leptin values in pre- and postmenopausal women. The existing clinical data on this issue are discordant.

Conclusion: Larger clinical studies are necessary to clarify leptin's role in vivo and to assess the contribution of the central and peripheral role of leptin in the overall maintenance of bone turnover in human beings.

\section{INTRODUCTION}

Leptin, a member of the helical cytokine family is the soluble 16-kDa product of the $O B$ (Lep) (Ob for obese and Lep for leptin) gene on human chromosome $7 \mathrm{q} 31.3$ and chromosome 6 in mouse ${ }^{1}$. Leptin is mainly produced by white fat cells, it is also produced by brown adipose tissue, placenta (syncytiotrophoblasts), ovaries, skeletal muscle, stomach (lower part of fundic glands), mammary epithelial cells, bone marrow, pituitary and liver ${ }^{1}$. Leptin first emerged as a component of a regulatory loop linking fat mass to food intake and energy expenditure but later also raised considerable interest as a potential mediator of the protective effects of fat mass on bone tissue ${ }^{2}$. The protective effect of obesity on bone mass has been ascribed to a high body fat content. Leptin is produced by adipose cells, with its levels reflecting the amount of adipose tissue, so leptin logically emerged as a possible mediator of protectice effect of fat tissue on bone. Leptin exerts its effects through interaction with six types of receptors. Leptin receptors are divided into secretory ( $\mathrm{ObRe})$, long $(\mathrm{ObRb})$ and short forms (ObRa, ObRc, ObRd, ObRf). $(\mathrm{ObRe})$ acts as a binding protein for leptin in the plasma in humans and mice and is important for leptin transfer into the brain. $\mathrm{ObRb}$ is the only receptor isoform that contains active intracellular signaling domains. This receptor is found in a number of hypothalamic nuclei where it exerts its effects. ObRb receptors are also found in other cells including osteoblasts. Leptin binds to the Ventral Medial nucleus of the hypothalamus, known as the "satiety center" where it signals to the brain a sensa- tion of satiety. Leptin also works by inhibiting the activity of neurons that contai the neuropeptide Y (NPY) and agouti-related peptide (AgRP), and stimulating neurons expressing $\alpha$-melanocyte-stimulating hormone ( $\alpha$-MSH). The NPY neurons are a key element in the regulation of appetite. Once leptin has bound to the $\mathrm{Ob}-\mathrm{Rb}$ receptor, it activates the stst 3 molecule, which is then phosphorylated and travels to the nucleus, where it is presumed, to effect changes in gene expression. One of the main effects on gene expression is the down-regulation of the expression of the endocannabinoids, responsible inter alia for increasing appetite. There are several other intracellular pathways activated by leptin, but less is known about how they function in this system.

\section{Mechanism of leptin action on bone}

The exact influence of leptin on bone metabolism has not yet been clarified. The literature is inconsistent and conflicting. Leptin is emerging as central in two entirely different bone -controlling mechanisms. The first is the indirect one. It was discovered by Ducy and al..$^{3-8}$ in mutant mice and rats that either cannot produce or cannot respond to, leptin. Leptin secreted from fat cells is carried by the ObRa receptors of vascular endothelial cells across the blood-brain-barrier where it activates $\mathrm{ObRb}$ receptors in the hypothalamus. These signals then stimulace expression of HOBIF (hypothalamic osteoblast inhibitory factor) which when released, lowers the matrix-making ability of osteoblasts ${ }^{2-8}$. These authors discovered what they believed to be the reason why obese $\mathrm{Ob}(\mathrm{Lep})^{-/-}$mice, which should have low bone mass because of their lack 
of leptin, and thus estrogen, actually have an abnormally high bone mass ${ }^{3-8}$. They found that intracerebroventricular injections of leptin actually caused the bone mass to decrease. It is assumed that leptin stimulates the brain to release HOBIF. Another part of central control mechanism of leptin is the NPY and its Y2 receptor, which may stimulate HOBIF release. In mice lacking neuropeptide 2 (NPY2) receptors in the hypothalamus deletion of hypothalamic NPY2 receptors resulted in increased bone mass without any obvious endocrine imbalance that would affect bone homoeostasis, which shows that these receptors regulate bone formation by alterating autonomic function ${ }^{9}$. A loss of either Y2 receptors or leptin should reduce HOBIF and increase osteoblast productivity ${ }^{9}$. Elefteriou et al.$^{10}$ found that NPY-deficient mice have normal bone mass, which is in contrast to the mice deficient in NPY2 receptor. NPY4 receptor deficient mice have normal bone mass, whereas double knockout of NPY2 and NPY4 receptors leads to a greater increase in bone volume than in mice deficient only in the NPY2 receptor ${ }^{11}$. Both receptors modulate sympathetic outflow in the brain stem. Augmented bone formation in the double knockout mouse suggests synergistic activity between NPY2 and NPY4 receptor pathways ${ }^{11}$. The second direct mechanism of leptin exerts its osteotrophic effects by promoting differentiation of bone marrow stromal cells into osteoblasts ${ }^{12}$ and by inhibiting osteoclast generation ${ }^{13}$. Circulating leptin penetrates the bone marrow, where it joins the autocrine/ paracrine leptin from early cells of the osteoblast lineage and from late-stage, matrix-mineralizing osteoblasts or from early osteocytes to stimulate the production of IGF1. IGF-1 in turn stimulates the proliferation of osteoblast precursors makes the osteoblastic lineage cells more resistant to apoptosis, and further enhances bone formation through suppression of osteoclast generation by causing osteoblastic stromal cells to make less RANKL (NF-kappaB ligand) which stimulates osteoclast generation, and by stimulating the production of the osteoclast-suppressing OPG (osteoprotegerine) the osteoclast suppressor. Osteoblasts freshly isolated from adult humans have functional ObRb receptors ${ }^{14}$. Bassilana et al. ${ }^{15}$ have found that human mesenchymal stem cells begin expressing both the nonfunctional, leptin transvascular-transporting $\mathrm{ObRa}$, the fully functional long ObRb signal-transducing receptors, and leptin itself during osteoblastic differentiation. Reseland te al. ${ }^{16}$ have found that human osteoblasts start making and secreting leptin when they are either in the late, matrix-mineralizing stage or when changing to osteocytes. Leptin has also stimulates the proliferation of cultured human osteoblasts ${ }^{17}$, and it has been shown to cause human bone marrow stromal cells to express alkaline phosphatase, collagen-I, and osteocalcin and to mineralize matrix ${ }^{12}$.

Although data from cultured human bone cells point to leptin as a direct stimulator of bone growth and a suppressor of bone resorption, the correlation between the serum leptin level and BMD (bone mineral density) in humans is so far equivocal, possibly because of a shifting balance between the cytokine's stimulatory direct action and sup- pressive indirect action on bones via the hypothalamus. In human beings, positive, negative, or no associations between serum leptin levels and bone mineral density have been reported. Pasco et al. ${ }^{18}$ have reported that serum leptin levels are positively correlated to the bone mineral content. Results of Blain et al. ${ }^{19}$ demonstrated that leptin is an independent predictor of whole body and femoral neck BMD in postmenopausal women. Yamauchi et al. ${ }^{20}$ showed that in postmenopausal women plasma leptin levels were positively correlated with BMD values. Moreover, plasma leptin levels were significantly lower in women with vertebral fractures than in those without fractures. The study of Di Tomaselli et al. ${ }^{21}$ also confirms a significant correlation between serum leptin and BMD in early postmenopausal women, but the correlation was lost during progression of the postmenopausal period. Thomas et al. ${ }^{22}$ have reported that BMD is positively correlated to fat mass and the serum leptin level in women. Z. Nagy et al. ${ }^{23}$ found a negative correlation between serum leptin levels and radial and femoral BMD in postmenopausal women. On the other hand P. Hadji et al. ${ }^{24}$ reported that bone mass is not correlated with the serum leptin level in pre or postmenopausal women. Goulding et al. found no significant correlations between plasma leptin and dynamic markers of bone resorption or formation ${ }^{25}$. Rauch et al. also failed to find a relationship between bone mass and serum leptin levels by examining total and trabecular bone density at the distalradius in adult women and reported no correlation, between plasma leptin level and bone turnover markers in adult women ${ }^{26}$.

\section{Differences in leptin levels between men and women}

Leptin possesses dimorphism, it is higher in women than in men. Leptin pulse amplitude is two to three times higher in women than in men and the expression rate of leptin mRNA in subcutaneous fat tissue is significantly higher in females than in males ${ }^{27}$. Moreover, in vitro, the leptin secretion rate of men's subcutaneous adipose tissue is $66 \%$ that of women's ${ }^{28}$. This would suggest a dependence of leptin on estrogen. Some authors admitt the difference may result not from higher estrogen level in women, rather from a suppressive effect of high levels of circulating androgens in men on leptin production ${ }^{29,}{ }^{30}$. It has been suggested that androgens reduce the regulation of leptin secretion ${ }^{29,31}$. Administration of testosterone reduces the expression of leptin mRNA in men. However, the influence of circulating androgens is not supported by other studies ${ }^{33,34}$. In these studies, leptin levels were invertly correlated with androgen levels.

\section{Leptin and menopause}

Postmenopausal women, whose estrogen levels naturally or artificially decline, are at the highest risk for developing osteopenia and osteoporosis. The influence of hormonal changes during menopause on leptin levels is still poorly understood. It is well documented that the serum concentration of leptin secreted by adipocytes correlates positively with the amount of fat mass and $\mathrm{BMI}^{35-}$ 38. It appears that percent body fat in postmenopausal 
women may be the best adiposity-related predictor of serum leptin ${ }^{39}$. As a consequence of the decline in endogenous estrogens and reduced energy during menopause women tend to gain body fat ${ }^{40}$. After menopause heavier women conserve bone mass better than those with lower body weight. The protective effect of obesity on bone mass has been ascribed to a high body fat content. As a result of menopause transition the levels of circulating estrogens decrease whereas the adrenal glands continue to secrete androgen precursors. Inactive steroid precursors are aromatized to estrogens in adipose tissue. The relative increase in the androgen/estrogen ratio is likely to be important for the fat distribution shift ${ }^{41}$. Postmenopausal women manifest shift to a abdominal fat distribution (android type of obesity), which is associated with a more androgenic profile with increased free testosterone levels and lower sex hormone-binding globulin (SHBG) levels. The shift to abdominal adiposity shows itself in the changes of WHR (waist to hip ratio). The connection between serum leptin concentration and WHR is controversial. Some authors have shown that serum leptin levels are higher in android obese women than in gynoid ones $^{42}$, but other studies demonstrate a lack of correlation between serum leptin concentration and the type of obesity. Martinez-Carpio et al. found no correlation between leptin and WHR in postmenopausal women, but they found significant correlations between leptin and weight, BMI and chest, waist and hip circumferences ${ }^{43}$. This is in agreement with the results of Tupikowska and Minocci et al. ${ }^{34,44}$. They also showed that WHR values were not correlated with leptin concentrations ${ }^{44}$. They suggest that subcutaneous abdominal fat is a determinant of leptin concentration, independently of the amount of fat mass, whereas the contribution of preperitoneal visceral fat is not significant.

Various studies have shown differences in leptin values in pre- and postmenopausal women. Some authors suggest that serum leptin concentration are lower in the post-menopausal period. Rosenbaum et al. ${ }^{29}$ Shimizu et al. ${ }^{45}$ They report that pre-menopausal women have higher leptin production than postmenopausal women. However there are also reports indicating that decrease in estrogen levels in postmenopausal status has no direct effect on adipose tissue leptin production or concentrations ${ }^{31,34 \text {, }}$ ${ }^{45-48}$. There are only few studies comparing the leptin level in women with artificially induced menopause before and after ovarectomy. When women with previously normal cycles before surgery were studied during the fourth postoperative day period after bilateral ovariectomy a significant reduction in leptin concentrations was found. There was a positive correlation of leptin values with estradiol and progesterone before and after the operation ${ }^{49}$.

Several authors have investigated plasma leptin levels in postmenopausal women during administration of HRT (hormone replacement therapy). Some results show that estrogens can regulate leptin production and its serum concentration ${ }^{45}$. Some studies reported no differences in serum leptin levels between users and non - users of hormonal replacement therapy, while others showed both de- creased and increased leptin levels. Existing clinical data addressing this issue are discordant. Di Carlo et al. ${ }^{50}$ found increased serum leptin level in untreated postmenopausal women decreased to premenopausal values after hormonal treatment. These results suggested that sex hormone replacement therapy can modulate leptin levels. In obese and non-obese postmenopausal women studied before and after HRT administration, plasma leptin levels showed an increase following treatment which was more pronounced in obese women ${ }^{51}$. Also intranasal and oral HRT had the effect of increasing the levels of leptin after 24 weeks in healthy postmenopausal women ${ }^{52}$. Other authors indicate that neither endogenous E2 nor sex hormone replacement therapy has any effect on serum leptin concentration ${ }^{34}$. These results support the hypothesis that the expression of leptin in adipocytes and circulating levels of this hormone are not related to the estrogen levels and type of hormonal therapy used. Hickey et al. analyzed data on postmenopausal women taking part in a cardiovascular risk factor study and found that leptin concentrations were similar in sex hormone users and non-users ${ }^{53}$. Also the results of the San Antonio heart study also showed no relation between serum leptin levels and menopausal status or postmenopausal sex hormone use ${ }^{54}$. Gower et al. compared HRTtreated postmenopausal women with untreated controls. There were no significant determinants of serum leptin levels ${ }^{55}$. In a randomized placebo-controlled study in postmenopausal women with type 2 diabetes mellitus treated with transdermal E2 + NETA (estradiol + norethisteorne acetate), no significant alterations in leptin levels were found $^{56}$. The group of Di Tomaselli evaluated serum leptin levels in healthy HRT treated and untreated postmenopausal women. In women taking HRT, serum leptin levels did not change significantly throughout the study period ${ }^{57}$. In an large sample of healthy postmenopausal users and non-users of hormone replacement therapy, Hadji et al. showed that neither sex hormone supplementation nor serum estrogen concentrations had any effect on leptin concentration, even after adjustment for $\mathrm{BMI}^{24}$. Other investigators take the possibility into account that differences in leptin level may depend on the type and dose of HRT used ${ }^{58}$. Gower et al. measured leptin in women with an untreated spontaneous cycle and with a cycle treated withdifferent types of HRT. Women treated with estradiol plus progesterone had elevated serum leptin concentrations, but when estradiol was administered alone, leptin concentrations were not affected ${ }^{56}$. Serum leptin levels were increased in postmenopausal women treated with short-term HRT independent of changes in fat mass; in the same women, progesterone administration alone did not influence leptin levels. Some authors suggest that only a supraphysiological estrogen concentration can act on adipocytes and modulate leptin production. It is possible that different doses of estradiol exert a more pronounced effect on circulating leptin ${ }^{59}$. Also studies in women with artificial menopause show similar results. Messinis et al. studied leptin levels in ovariectomized normal women treated with estradiol plus progesterone ${ }^{60}$. They found that HRT prevented the ovariectomy -induced decrease in lep- 
tin levels ${ }^{59,61}$. On the other hand administration of HRT to ovariectomized women starting 15 days after surgery did not modify leptin levels ${ }^{62}$.

\section{Leptin administration as a treatment for osteopenia}

Leptin might be used to treat osteopenia only if it can be engineered to avoid suppressive indirect effects on bones via the hypothalamus - avoid the hypothalamus and refrain from stimulating HOBIF expression. Only a very small group of humans is knowm to possess homozygous mutations for the leptin gene. Up to date, two United Kingdom families of Pakistani origin carrying a frameshift/premature mutation, and one Turkish family carrying a missense mutation, have been described ${ }^{21}$. This mutation leads to a constant demand for food, resulting in severe obesity. This condition can be successfully treated by the administration of recombinant human leptin and theroretically administration of leptin could be used to treat osteopenia in these subjects.

\section{CONCLUSION}

Although data from cultured human bone cells point to leptin as a direct stimulator of bone growth and a suppressor of bone resorption, understanding of leptin's role in human bone-remodelling is not yet defined. The exact role of leptin on bone mass remains unclear. The correlation between the serum leptin levels and BMD in humans is so far equivocal, possibly because of a shifting balance between the cytokine's stimulatory direct action and suppressive indirect action on bones via the hypothalamus. The effect that oestrogen decrease and deficiency during menopause and administration of hormone replacement therapy has on leptin production and contribution of leptin on emergence of osteopenia remains controversial. Existing clinical data addressing this issue are discordant. Larger clinical studies are therefore necessary to clarify leptin's role in vivo and to assess the contribution of the central and peripheral role of leptin to the overall maintenance of bone turnover in human beings and how leptin contributes to the mechanism of loss of bone mass during artificial and natural menopause.

\section{REFERENCES}

1. Whitfield JF. Leptin: brains and bones. Exp Opin Invest Drugs. 2001;10:1617-1622.

2. Halaas JL, Gajiwala KS, Maffei M, Cohen SL, Chait BT, Rabinowitz $\mathrm{D}$, et al. Weight reducing effects of the plasma protein encoded by the ob gene. Science 1995; 269: 543-546.

3. Amling M, Takeda S, Karsenty G. A neuro(endo)crine regulation of bone remodeling. Bioessays. 2000;22:970-975.

4. Ducy P, Amling M, Takeda S. Leptin inhibits bone formation through a hypothalamic relay. Cell. 2000;100:197-207.

5. Ducy P, Schinke T, Karsenty G. The osteoblast: a sophisticated fibroblast under central surveillance. Science. 2000;289:15011504.

6. Karsenty G. The central regulation of bone remodeling. Trends Endocrinol Metab. 2000;11:437-439.
7. Karsenty G. Leptin controls bone formation through a hypothalamic relay. Recent Prog Horm Res. 2001;56:401-415.

8. Takeda S, Karsenty G. Central control of bone formation. J Bone Miner Metab. 2001;19:195-198.

9. Baldock PA, Sainsbury A, Couzens M. Hypothalamic Y2 receptors regulate bone formation. J Clin Invest 2002; 109:915-921.

10. Elefteriou F, Takeda S, Liu X, Armstrong D, Karsenty G. Monosodium glutamate-sensitive hypothalamic neurons contribute to the control of bone mass. Endocrinology 2003; 144:38423847.

11. Sainsbury A, Baldock PA, Schwarzer C. Synergistic effects of Y2and Y4 receptors on adiposity and bone mass revealed in double knockout mice. Mol Cell Biol 2003; 23:5225-5333.

12. Thomas T, Gori F, Khosla S, Jensen MD, Burguera B, Riggs BL. Leptin acts on human marrow stromal cells to enhance differentiation to osteoblasts and to inhibit differentiation to adipocytes. Endocrinology 1999; 140:1630-1638.

13. Holloway WR, Collier FM, Aitken CJ, Myers DE, Hodge JM, Malakellis M, et al.. Leptin inhibits osteoclast generation. Journal of Bone and Mineral Research 2002; 17:200-209.

14. Cornish J, Callon KE, Bava U. The direct actions of leptin on bone cells increase bone strength in vivo: an explanation of low frequency fracture rates in obesity. Bone. 2001;28:S88.

15. Bassilana F, Susa M, Keller HJ. Human mesenchymal stem cells undergoing osteogenic differentiation express leptin and functional leptin receptor. J Bone Miner Res. 2000;15:S378.

16. Reseland J, Syversen U, Bakke I. Leptin is expressed in and secreted from primary cultures of human osteoblasts and promotes bone mineralization. J Bone Miner Res. 2001; 16:1426-1433.

17. Evans BAJ, Elford C, Gregory JW. Leptin control of bone metabolism; direct or indirect action? Bone. 2001; 28:149.

18. Pasco JA, Henry MJ, Kotowicz MA. Serum leptin levels are associated with bone mass in non-obese women. J Clin Endocrinol Metab. 2001;86:1882-1883.

19. Blain H, Vuillemin A, Guillemin F. Serum leptin level is a predictor of bone mineral density in postmenopausal women. J Clin Endocrinol. 2002; 87: 1030-1035.

20. Yamauchi M, Sugimoto T, Yamaguchi T. Plasma leptin concentrations are associated with bone mineral density and the presence of vertebral fractures in postmenopausal women. Clin Endocrinol 2001;55:341-347.

21. Di Carlo C, Tommaselli GA, Gargano V, Sammartino A, Bifulco $\mathrm{G}$, Tauchmanova L et al. Effects of estrogen-progestin therapy on serum levels of RANKL, osteoprotegerin, osteocalcin, leptin, and ghrelin in postmenopausal women., Menopause 2007; 14:7-9.

22. Thomas T, Burguera B, Melton LJ. Role of serum leptin, insulin, and estrogen levels as potential mediators of the relationship between fat mass and bone mineral density in men versus women. Bone. 2001;29:114-120.

23. Nagy Z, Speer G, Takács I, Bajnok Č, Lakatos P. Serum leptin levels and bone mineral density in postmenopausal women. Program and abstracts from the Twenty-Third Annual Meeting of the American Society for Bone and Mineral Research; October 12-16, 2001; Phoenix, Arizona. Abstract SA346. J Bone Miner Res. 2001;16(suppl 1):S284.

24. Hadji P, Bock K, Gottschalk M, Kalder M, Emons G, Shulz KD. The influence of serum leptin concentrations on bone mass assessed by quantitative ultrasonometry (QUS) in pre- and postmenopausal women. Program and abstracts from the Twenty-Third Annual Meeting of the American Society for Bone and Mineral Research; October 12-16, 2001; Phoenix, Arizona. Abstract SA008. J Bone Miner Res. 2001;16(suppl 1):S233.

25. Goulding A, Taylor RW. Plasma leptin values in relation to bone mass and density and to dynamic biochemical markers of bone resorption and formation in postmenopausal women. Calcif Tissue Int 1998; 63:456-458.

26. Rauch F, Blum WF, Klein K, Allolio B, Schönau E. Does Leptin Have an Effect on Bone in Adult Women? Calcif Tissue Int 1998; 63:453-455.

27. Havel PJ, Kasim-Karakas S, Dubuc GR, Mueller W, Phinney SD. Gender differences in plasma leptin concentrations. Nat Med 1996;2:949-950. 
28. Di Carlo C, Tommaselli G, Nappi C. Effects of sex steroidhormones and menopause on serum leptin concentrations. Gynecol Endocrinol 2002;16:479-491.

29. Rosenbaum M, Nicolson M, Hirsch J, Heymsfield SB,Gallagher D, Chu F, Leibel RL. Effects of gender, body composition, and menopause on plasma concentrations leptin. J Clin Endocrino Metab 1996;81:3424-3427.

30. Elbers JM, Asscheman H, Seidell JC, Frolich M, Meinders AE, Gooren LJ. Reversal of the sex difference in serum leptin levels upon cross-sex hormone administration in transsexuals.J Clin Endocrinol Metab 1997;82:3267-3270.

31. Hadji P, Gorke K, Hars O, Bauer T, Emons G, Schulz KD. The influence of hormone replacement therapy (HRT) on serum leptin concentrations in postmenopausal women. Maturitas 2000;37:105111.

32. Wu-Peng S, Rosenbaum M, Nicolson M, Chua SC, Leibel RL. Effects of exogenous gonadal steroids on leptin homeostasis in rats. Obes Res 1999;7:586-592.

33. Lambrinoudaki I, Christodoulakos G, Panoulis C, Botsis D, Rizos D, Augoulea A et al. Determinants of serum leptin levels in healthy postmenopausal women. J Endocrinol Invest 2003;26:12251230.

34. Tupikowka G, Filus A, Kuliczkowska J, Tupikowski K, Bohdanowicz - Pawlak A, Milewicz A.Serum leptin concentrations in pre- and postmenopausal women on sex hormone therapy, Gynecological Endocrinology. 2006; 22: 207-212.

35. Hadji P, Hars O, Bock K, Sturm G, Bauer T, Emons G et al.The influence of menopause and body mass index on serum leptin concentrations. Eur J Endocrinol 2000; 143:55-60.

36. Panidis DK, Rousso DH, Kourtis AI, Stergiopoulos KN, Mavromatidis GA, Katsikis IK. The influence of tibolone upon serum leptin levels in post-menopausal women. Eur J Obstet Gynecol Reprod Biol 2001;96:85-87.

37. Milewicz A, Bidzińska B, Mikulski E, Demissie Tworowska U. Influence of obesity and menopause on serum leptin, cholecystokinin, galanin and neuropeptide levels. Gynecol Endocrinol 2000;13:1-8.

38. Rajatanavin R. Change in body weight after hormone replacement therapy in postmenopausal women is dependent on basal circulating leptin. Maturitas 1998;30:283-288.

39. Mahabir S, Baer D, Johnson L, Roth M, Campbell W, Clevidence $B$ et al. Body Mass Index, percent body fat, and regional body fat distribution in relation to leptin concentrations in healthy, nonsmoking postmenopausal women in a feeding study. Nutr J. 2007, 6: 3

40. Poehlman ET, Toth MJ, Gardner AW. Changes in energybalance and body composition at menopause: a controlled longitudinal study. Ann Intern Med 1995;123:673-5.

41. Lovejoy JC. The menopause and obesity. Prim Care 2003;30:31725.

42. Garaulet M, Perex-Llamas F, Fuente T, Zamora S. Anthropometric, computed tomography and fat cell data obese population: relationship with insulin, leptin, tumor necrosis factor-a, sex hormone-binding globulin and hormones. Eur J Endocrinol 2000;143:657-666.

43. Martinez-Carpio PA, Fiol C, Hurtado I, Hurtado I, Arias C,Ruiz $\mathrm{E}$ et al. Relation between leptin and body fat distribution in menopausal status. J Physiol Biochem 2003;59:301-307.

44. Minocci A, Savia G, Lucantoni R, Berselli ME, Tagliaferri M,Calo $\mathrm{G}$ et al. Leptin plasma concentrations are dependent on body fat distribution in obese patients. Int J Obes Relat Metab Disord 2000;24:1139-1144

45. Shimizu H, Shimomura Y, Nakanishi Y, Futawatari T, Ohtani K, Sato $\mathrm{N}$ et al. Estrogen increases in vivo leptin production in rats and human subjects. J Endocrinol 1997; 154: 285-292.
46. Kristensen K, Pedersen SB, Richelsen B. Interactions between sex steroid hormones and leptin in women. Studies in vivo and in vitro. Int J Obes Relat Metab Disord 2000; 24: 1438-1444.

47. Pelleymounter MA, Baker MB, McCaleb M. Does estradiol mediate leptin's effects on adiposity and body weight? Am J Physiol 1999; Vol. 276, Issue 5: 955-963

48. Douchi T, Iwamoto I, Yoshimitsu N, Kosha S, Nagata Y. Leptin production in pre- and postmenopausal women. Maturitas 2002; Volume 42, Number 3, 25 July 2002, 219-223(5)

49. Messinis IE, Milingos SD, Alexandris E, Kariotis I, Kollios G, Seferiadis K. Leptin concentrations in normal women following bilateral ovariectomy. Hum Reprod 1999; 14:913-18.

50. Di Carlo C, Tommaselli GA, Pisano G, Nasti A, Rossi V, Palomba S. Serum leptin levels in postmenopausal women: effect of transdermal hormone replacement therapy. Menopause 2000;7:36-41.

51. Konukoglu D, Serin O, ErcanM. Plasma leptin levels in obese and non-obese postmenopausal women before and after hormone replacement therapy. Maturitas 2000;36:203-7.

52. Castello-Branco, Palacios S, Vázquez F, Villero J, Ferrer J, Ascaso $\mathrm{C}$ et al. Effects on serum lipid and leptin levels of three different doses of norethisterone continuously combined with a fixed dose of 17 beta-estradiol for nasal administration in postmenopausal women: a controlled, double-blind study, Fertil. Steril 2007;88(2):3839.

53. Hickey MS, Gardiner SN, Thomson DP, Barakat HA. Gender differences in plasma leptin concentration are not influenced by menopause or hormone replacement therapy. Med Sci Res 1998;26:271-273.

54. Haffner SM, Mykkanen L, Stern MP. Leptin concentrationsin women in the San Antonio heart study: effect of menopausa status and postmenopausal hormone replacement therapy. Am J Epidemiol 1997; 146:581-585.

55. Gower BA, Nagy TR, Goran MI, Smith A, Kent E. Leptin inpostmenopausal women: influence of hormone therapy, insulin, and fat distribution. J Clin Endocrinol Metab 2000;85:1770-5.

56. Perera M, Sattar N, Petrie Jr, Hillier C, Small M, Connell JM, et al. The effects of transdermal estradiol in combination with oral norethisterone on lipoproteins,coagulation, and endothelial markers in postmenopausalwomen with type 2 diabetes: a randomized, placebo-controlled study. J Clin Endocrinol Metab 2001;86:1140-3.

57. Di Carlo C, Tommaselli GA, Sammartino A, Bifulco G, NastiA, Nappi C. Serum leptin levels and body composition in post menopausal women: effects of hormone therapy. Menopause 2004;11:466-73.

58. Lin KC. Increase of leptin levels following exogenousadministration of estrogen in women with normal menstruation. Kaohsiung J Med Sci 2000;16;13-19.

59. Lavoie HB, Taylor AE, Sharpless JL, Anderson EJ, StraussCC, Hall JE. Effects of short- term hormone replacement on serum leptin levels in postmenopausal women. Clin Endocrinol (Oxf) 1999;51:415-22.

60. Messinis IE, Milingos SD, Alexandris E, Kariotis I, Kollios G, Seferiadis K. Leptin concentrations in normal women following bilateral ovariectomy. Hum Reprod 1999; 14:913-18.

61. Messinis IE, Kariotis I, Milingos S, Kollios G, Seferiadis K Treatment of normal women with oestradiol plus progesterone prevents the decrease of leptin concentrations induced by ovariectomy. Hum Reprod 2000;15:2383-7.

62. Tommasell GA, Giovanni A, Di Carlo C. Effects of bilateral ovariectomy and postoperative hormonal replacement therapy with 17 [beta]-estradiol or raloxifene on serum leptin levels. Menopause 2003; 10(2):160-164. 